\title{
Optimal design of building openings to reduce the risk of indoor respiratory epidemic infections
}

\author{
Yixin Dong' ${ }^{1}$, Li Zhu ${ }^{1,3}(\bowtie)$, Sui Li' ${ }^{4}$, Martin Wollensak ${ }^{2}$ \\ 1. School of Architecture, Tianjin University, Tianjin, 300072, China \\ 2. School of Architecture and Design, Hochschule Wismar, Wismar, 23966, Germany \\ 3. APEC Sustainable Energy Center, Asia-Pacific Economic Cooperation (APEC), National Energy Administration (NEA) of China, Tianjin, \\ 300072, China \\ 4. Ecological Planning and Green Building Research Institute, Shenyang Jianzhu University, Shenyang, 110168, China
}

\section{Abstract}

The design of indoor airflow environments can significantly reduce the risk of respiratory epidemic infections indoors. Some studies have successfully developed theoretical models for calculating the effect of airflow fields on infection rates. However, up until now, studies have primarily focused on simulating and calculating the distribution of viral infection rates in current building scenarios. Due to the lack of a direct influence model for the design parameters and infection rate calculation, the present studies lack a quantitative analysis of the design parameters. This paper investigates the building openings design approach in a medium-sized kindergarten in Germany, intending to explore passive-based design solutions to improve the building's ability to prevent the virus' spread. We calculate the infection rate distribution in space by CFD combined with the Wells-Riley model. And then, use the Grasshopper platform to build an optimization model with the design parameters of building openings and infection rate values to discuss the relationship between geometric parameters and infection rate variation. The results show that the building openings' design parameters in transition spaces significantly affect the indoor infection rate under the condition that the input wind speed at the building openings is stable. We can see that optimizing building openings significantly reduces the average infection rate in space. The infection rate in the area with the largest decrease can be reduced by $18.41 \%$. The distribution of infection rate in space is much more uniform, and the excess area is significantly reduced. This study has implications for future research and practice in designing public buildings under the influence of long-standing and cyclical outbreaks of epidemics.
\end{abstract}

\section{Keywords}

virus infection rate; building openings; parameter optimization; transition spaces; COVID-19; parametric simulation

\section{Article History}

Received: 18 May 2021

Revised: 29 August 2021

Accepted: 30 August 2021

() Tsinghua University Press and Springer-Verlag GmbH Germany, part of Springer Nature 2021

\section{Introduction}

The recent global COVID-19 pandemic has shown that the spread of respiratory diseases in public places poses a severe threat to world public health security (Wu et al. 2020; Zhou et al. 2020). Due to social and productive human activity laws, the risk of epidemic transmission is much higher in indoor spaces of public buildings than in outdoor areas (Chen et al. 2020). The pattern of global respiratory epidemic outbreaks over the past 150 years shows a significant shortening of the interval between disease cycles (Chan-Yeung and $\mathrm{Xu}$
2003; Mills et al. 2004; Valleron et al. 2010), the time interval between a pandemic of H1N1 influenza and a pandemic of COVID-19 is only about ten years (Chan-Yeung and Xu 2003; Chen et al. 2020). The shortening of the pandemic interval will have a more frequent impact on public buildings. The average lifespan of buildings varies worldwide (Balaras et al. 2005); in the case of China, where the average building is only 50 years old ( $\mathrm{Hu}$ and Zheng 2015), a building will experience at least two or more three severe global respiratory epidemics during its lifetime.

In the context of the regular impact of the epidemic on

E-mail: 814959126@qq.com 
the use of public buildings, new strategies for building operations and design are expected to play a major role in reducing the risk of transmission in the use of public buildings (Pavón et al. 2020). Many studies have shown that respiratory disease transmission pathways are directly related to indoor airflow (Xie et al. 2007; Wei and Li 2015). The planning and design of an indoor airflow environment can reduce the accumulation of exhaled pollutants and effectively reduce the risk of cross-infection of viruses in indoor air (Qian et al. 2009; Zhang 2020). The research questions in this study are: (1) How does the design of building openings impact the rate of virus infection indoor? (2) What are the best solutions in architectural design to reduce the rate of virus infection indoor? In order to effectively explore these issues, more needs to be known about the changing relationships between building design parameters, indoor airflow environment, and virus infection rate calculations. To assess whether optimization for design parameters can deterministically reduce indoor virus infection rates, we used digital methods to develop an optimization model and tested the dynamic association between building opening parameters and indoor virus infection rates.

In early studies of calculating indoor viral infection rates, scholars developed the Wells-Riley equation to predict the risk of airborne infection using the concept of quantitative infection (Wells 1955; Riley et al. 1978). Subsequent researchers have proposed various improvements to the underlying model, adding effects on filtration, particle deposition (Fisk et al. 2003), and respirators (Fennelly and Nardell 1998), as well as non-stationary states (Rudnick and Milton 2003). The Wells-Riley equation can only be calculated for infection rates in a single confined space and assumes that the droplet nuclei with the virus are uniformly distributed in space. However, existing studies on airborne diseases show that, in reality, particles with viruses are unevenly distributed in space, depending on factors such as the location of patients and susceptibles and the airflow patterns in space (Olsen et al. 2003; Wong et al. 2004; Yu et al. 2005; Noakes and Sleigh 2009). To calculate the infection rate of indoor viruses more realistically, scholars have tried to apply the hydrodynamic model to the infection rate calculation model and conducted a lot of research and experiments, including indoor monitoring experiments (Bjørn and Nielsen 2002; Qian et al. 2004; Qian et al. 2008; Lai and Wong 2010; Nielsen et al. 2014), numerical simulations (Qian et al. 2008; Srebric et al. 2008; Mui et al. 2009; Ji et al. 2018), and analytical models (Xie et al. 2007; Redrow et al. 2011; Wei and Li 2015; Liu et al. 2019). The CFD numerical simulation method has been widely studied for the calculation of the distribution of particulate pollutants (Qian et al. 2009; Chavez et al. 2011).

However, up until now, activity modeling has largely focused on simulating and calculating the distribution of viral infection rates in current building scenarios. While attempts have been made to further influence indoor ventilation patterns and alter the indoor airflow environment to reduce indoor infection rates (Qian et al. 2008; Qian et al. 2009; Chavez et al. 2011), current research models still have serious limitations when discussing optimization regarding design solutions. An extension of these models was later supported by digital technology. The proposed extensions include exploring the impact of building vent design on indoor infection rate calculations, but the original models used for simulation calculations remain unchanged (Du et al. 2020). Recognizing the limitations of simulation models for building design optimization, scholars have begun to discuss the relationship between design form and infection rates in more depth. Experiments investigating the effect of different airflow layers on the dispersion of spatial pollutants (Du et al. 2020) and experiments investigating the impact of individualized ventilation design on the risk of airborne transmission of COVID-19 viruses (Xu et al. 2020) have demonstrated the effectiveness of building design optimization in reducing indoor virus infection rates. However, due to the lack of a direct influence model for the design parameters and infection rate calculation, the current studies lack a quantitative analysis of the design parameters. The results of these studies do not directly guide the practice of building design and design renovation.

This paper would like to develop a parametric model that links a geometric optimization model to a viral infection rate calculation model based on previous research results. It can directly reflect the relationship between the influence of geometric parameters and the rate of virus infection. It can be used to quantify and discuss the degree of influence of both. The paper is structured as follows. Section 2 describes the modeling principles and methods of the parametric infection rate optimization model. Section 3 details the parametric model simulation and optimization experiments carried out based on a real public building case. Section 4 presents the computational results before and after the design optimization of openings for an actual public building. Section 5 details the analysis and discussion of the experimental data presented in this paper. Finally, we conclude by discussing the potential of the approach introduced in this paper, its shortcomings, and potential for improvement.

\section{Mathematical model}

\subsection{Wells-Riley model for integration with CFD}

The original Wells-Riley equation is based on the concept of quantal infection (Wells 1955). The equation can be written as: 
$P=\frac{C}{S}=1-\mathrm{e}^{-I q p t / Q}$

where $P$ is the probability of infection (risk), $S$ is the total number of susceptible individuals, and $C$ is the number of cases to develop an infection in the first outbreak. $I$ is the number of source patients (infected); $p$ is the pulmonary ventilation rate per minute in a susceptible $\left(\mathrm{m}^{3} / \mathrm{h}\right) ; Q$ is the room ventilation rate $\left(\mathrm{m}^{3} / \mathrm{h}\right) ; q$ is the quanta produced by an infected individual (quanta/h), and $t$ is the exposure time (h).

A susceptible person's risk of acquiring the disease through the air is related to the dose of pathogens (quanta) he/she inhales. The amount of virus inhaled by a susceptible person is related to the amount of pulmonary ventilation, the duration of exposure, and the concentration of virusbearing particles in inhaled air. Calculation of viral infection rates using Eq. (1) requires the ideal prerequisites of a single confined space and a uniform distribution of viral particles in that space. Thus, the concentration of viral particles in the inhalation air of a susceptible person can be defined as:

$$
N_{\mathrm{w}}=\frac{I q}{Q}
$$

where the concentration of virus-carrying particles $N_{\mathrm{W}}$ (concentration of quanta) in the space is determined only by the total number of virus particles (total number of quanta) produced by the theoretical source patient in the confined space and the overall ventilation (ignoring the effect of the indoor airflow field on the distribution of virus particles). Thus the Wells-Riley equation can only quantify the rate of viral infection in a space under exceptional circumstances and does not allow for an in-depth discussion of the distribution of infection rates in the space.

However, in reality, the spatial distribution of particles with viruses is not homogeneous. The quanta concentration at different locations depends on the patient's location, the virus's viability in the air, and the airflow pattern. The viability of airborne organisms varies under different environmental conditions, such as temperature, humidity, ultraviolet radiation (UV), etc. Under certain conditions, the death rate of microorganisms can be considered proportional to the number of living cells present in (Brundrett 1992) to facilitate the calculation of virus particle concentrations. The viability of the airborne organisms in a closed space may be written as (Brundrett 1992):

$$
-k N=\frac{\mathrm{d} N}{\mathrm{~d} t}
$$

Airborne organisms can attach to the tiny particles or droplet nuclei (Wells 1934; Brundrett 1992) and move through the air under the influence of air currents. Therefore, assuming that the distribution of airborne organisms is similar to the distribution of airborne particles (Holmberg and Li 1998), the control equation for the transport of airborne organisms in the air can be written as follows:

$$
\frac{\partial(\rho N)}{\partial t}+\nabla \cdot\left(\rho\left(\vec{V}+\vec{V}_{\mathrm{d}}\right) N\right)=\nabla \cdot\left(\frac{\mu_{\mathrm{eff}}}{\sigma_{N}} \nabla N\right)-k \rho N+S
$$

where $\vec{V}$ and $\vec{V}_{\mathrm{d}}$ are the velocity vector and settling velocity vector, respectively, and $\rho$ is the air density. The effect of particles on air density is ignored here and $\mu_{\text {eff }} / \sigma_{N}$ is the particles' diffusion coefficient (which can be set as a constant $\Gamma$ ). The settling velocity $V_{\mathrm{d}}$ is calculated by Stokes' law using the density and size of the particles. $S$ is the source term. $k$ is the constant death rate of airborne organisms in the air and is influenced by several factors. Only the effects of relative humidity and air temperature are considered and can be determined as constants. In the progress of CFD calculation, the indoor flow field and temperature field are solved firstly using the RNG $k-\varepsilon$ turbulence model, including buoyancy effect plus standard wall function. After the convergence is reached, Eq. (4) is solved solely based on the one-way coupling assumption (Holmberg and Li 1998; Gao and Niu 2007; Qian et al. 2009). Finally, we can obtain a more scientific distribution of $N$ : the quanta concentration (quanta $/ \mathrm{m}^{3}$ ).

According to the Wells-Riley equation, the escape probability $P_{\mathrm{E}}$ for one susceptible who inhales a particle concentration of $N$ for $t$ hours can be written as:

$P_{\mathrm{E}}=\mathrm{e}^{-N p t}$

Ignoring the fact that susceptible individuals are active in environments with different concentrations of virus quanta, the risk of infection $P$ can be calculated as:

$P=1-\mathrm{e}^{-N P T}$

\subsection{Model of the effect of building opening parameters on infection rates}

Equations (4) and (6) allow us to calculate the distribution of quanta concentration $(N)$ in space by bringing in the wind velocity $(V)$ at each point in space and then calculate the risk of virus infection and its distribution indoors. Based on this study, we would like to explore further how to control the indoor vector wind speed $(V)$ by design means, thus directly controlling the risk of virus infection. Geometric parameters essentially control the pattern and distribution of building openings in space. Four basic geometric parameters are extracted here: the number of building openings $\left(P_{n}\right)$, the width of openings $\left(P_{w}\right)$, the height/length of openings $\left(P_{h} / P_{l}\right)$, and the offset distance $\left(P_{d}\right)$ between the 
center of the openings and the center of the grid to which they belong. To exclude the effect of invalid samples on the experimental results, we qualified the functional relationship between the groups of variables as follows:

$$
\left\{\begin{array}{l}
P_{n} \times P_{w}+D_{1}+2 D_{2}=W \\
P_{n} \times P_{h}+D_{3}+2 D_{4}=H \\
P_{w} \leq W / n_{w} \\
P_{h} \leq H / n_{h} \\
P_{d w} \leq W / 2 n_{w}-P_{w} / 2 \\
P_{d h} \leq H / 2 n_{h}-P_{h} / 2
\end{array}\right.
$$

In Eq. (7), $W$ is the width of the interface, $H$ is the height or length of the interface, $D_{1}$ is the distance between openings in the $w$ direction, $D_{2}$ is the distance between openings to the interface boundary, $D_{3}$ is the distance between openings in the $h$ direction, and $D_{4}$ is the distance between openings to the interface boundary. We divide the grid in the interface enclosed in the $w$ and $h$ directions. The $n_{w}$ is the number of grids in the $w$ direction in the interface, and $n_{h}$ is the number of grids in the $h$ direction in the interface. $P_{d w}$ is the offset distance in the $w$ direction from the center of the building openings in the interface to which it belongs to the grid center, and $P_{d h}$ is the offset distance in the $h$ direction from the center of the building openings in the interface to which it belongs to the grid center.

A review of the preceding equations leads to two operational models, one for the optimization model of design parameters on the airflow environment. The other one is the calculation model for virus infection rate. We calculate the indoor vector wind speed as an interface between the above two models and fuse them to create a theoretical model that reflects the direct influence of geometric variables on virus infection rates. With the Grasshopper platform, the abovementioned theoretical models are parameter-programmed to create operational models that can be used for simulation calculations. A genetic algorithm program was then used to create an optimization channel for the geometric variables to discuss the relationship between the combinations of the variables on the virus infection rate (Figure 1). The model developed in this paper is based on parametric programming techniques to interface and integrate the Wells-Riley model, the CFD model, and the evolutionary algorithm. The results of previous validation studies of each individual model can indirectly demonstrate the feasibility and accuracy of this comprehensive model (Qian et al. 2009; Chavez et al. 2011; Ercan and Elias-Ozkan 2015).

\section{Simulation experiment based on Wismar kindergarten}

According to the study, kindergarten buildings are under enormous pressure during the epidemic, which will have a profoundly negative impact on children all over the world (Huang 2020). According to the federal data, 450,000 children will miss this grade in Germany in 2021 (Valerie 2021). In most areas during the epidemic, kindergarten buildings were

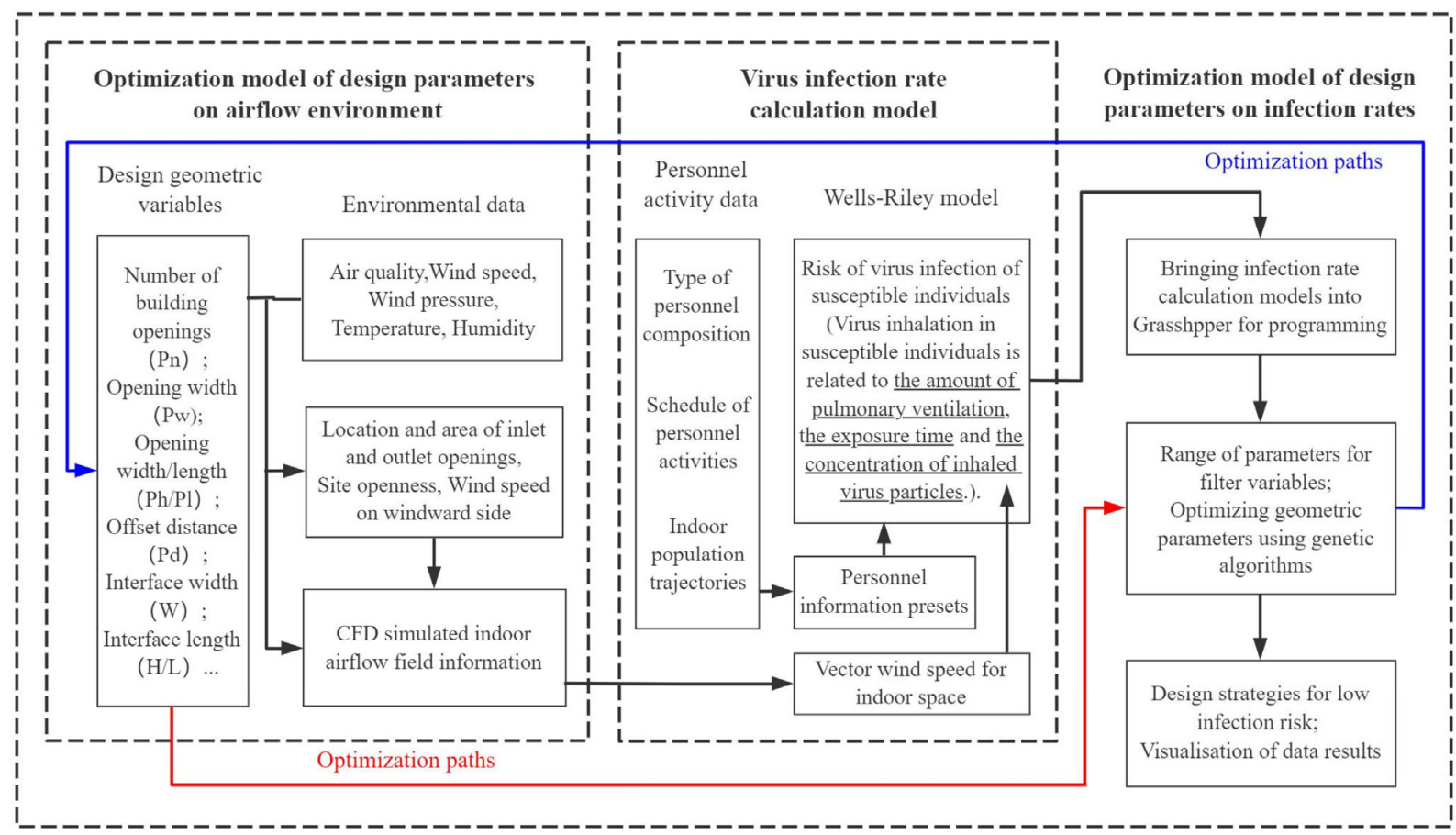

Fig. 1 Optimized model of building openings design parameters 
one of the first types of public buildings to be brought back into use due to social and productive needs and were at higher risk of infection (BBC News 2020).

The case of study is a medium-sized kindergarten building located in Wismar, Mecklenburg-Vorpommern, in the northern German region. The kindergarten building was chosen as the case study because we hope that the findings of this paper will help kindergarten buildings cope with the persistent epidemic situation. Next, we measured the building's design parameters and used the case data to create an introductory scenario for the simulation experiment.

\subsection{Experimental parameter design}

Based on the investigation of building usage, the building's transition spaces were divided into four specific regions (Figure 2), where the total number of existing building openings was 37 (23 window openings and 14 skylight openings). By measuring the wind velocity at the test points at the building openings (Figures 3 and 4), we were able to determine the primary location information for the air inlets and outlets at the building openings between August and October (when the school is in session in the fall) and the natural ventilation conditions at the building openings during the hours of use (7:00 to 17:00). After determining the average value of the input wind speed at the building's window openings during natural ventilation, the active replacement ventilation device was used to stabilize the wind speed in a range close to the average value of the natural ventilation wind speed. The values of the input wind speed at the building openings in this paper were $1.0-2.3 \mathrm{~m} / \mathrm{s}$ (August), $0.7-1.8 \mathrm{~m} / \mathrm{s}$ (September), and 1.6-2.5 m/s (October). Such values ensure a stable wind field environment in the space while using natural ventilation to organize the indoor airflow field for as long as possible during the hours of use and minimize active practices on ventilation.

Based on the basic information of the case building (Figure 2), we constructed a parametric simulation model (Figure 4). By measuring and organizing the building's current design indicators, the initial values and ranges of the building openings design's geometric parameters were determined for each of the four regions. According to the actual situation, the geometric variables were brought into the simulation and calculation model of the infection rate after a detailed description of the influence relationship and constraints between the different parameters (Table 1).

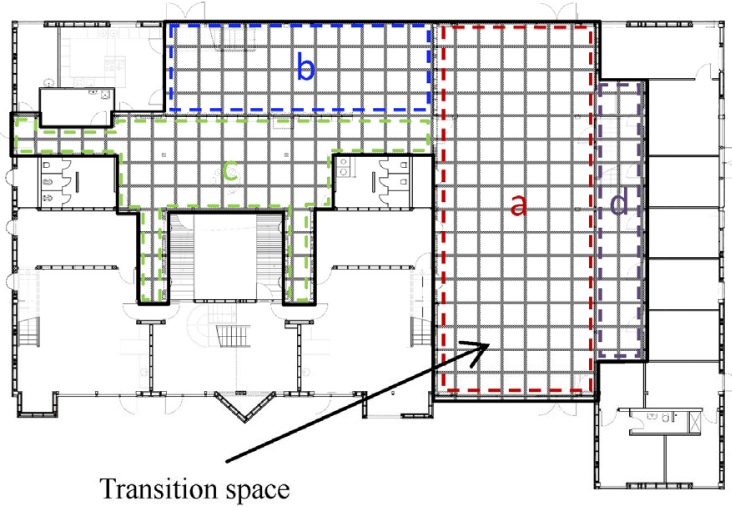

(a)

Fig. 2 Constructing a simulation scenario with case parameters

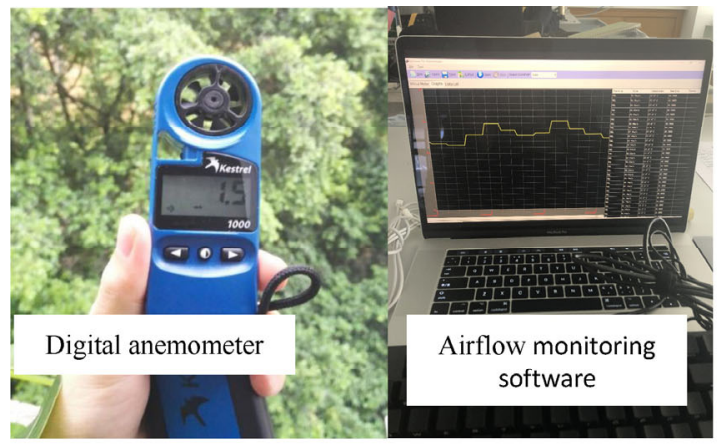

(a)

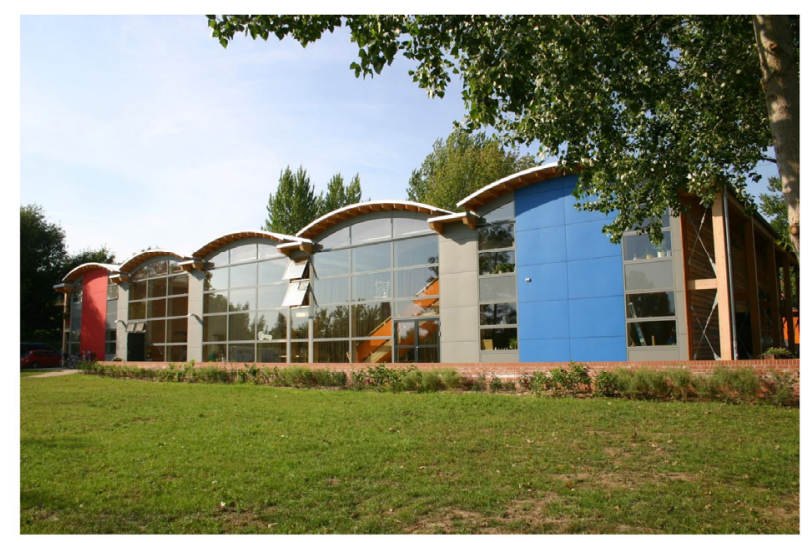

(b)

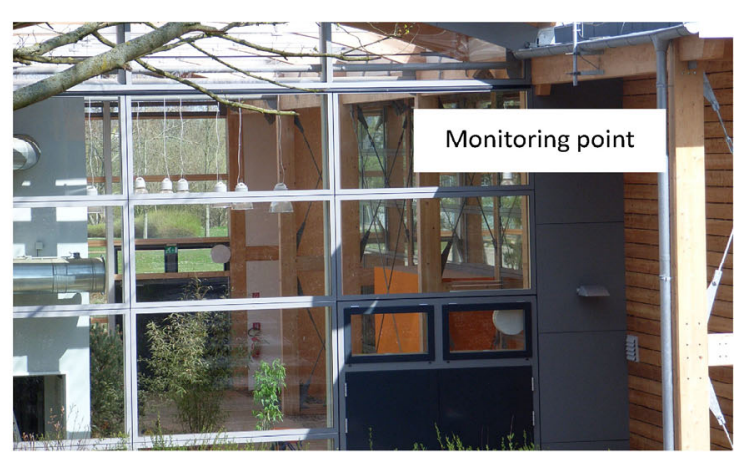

(b)

Fig. 3 Wind speed measurement sensor and real-time wind speed monitoring 


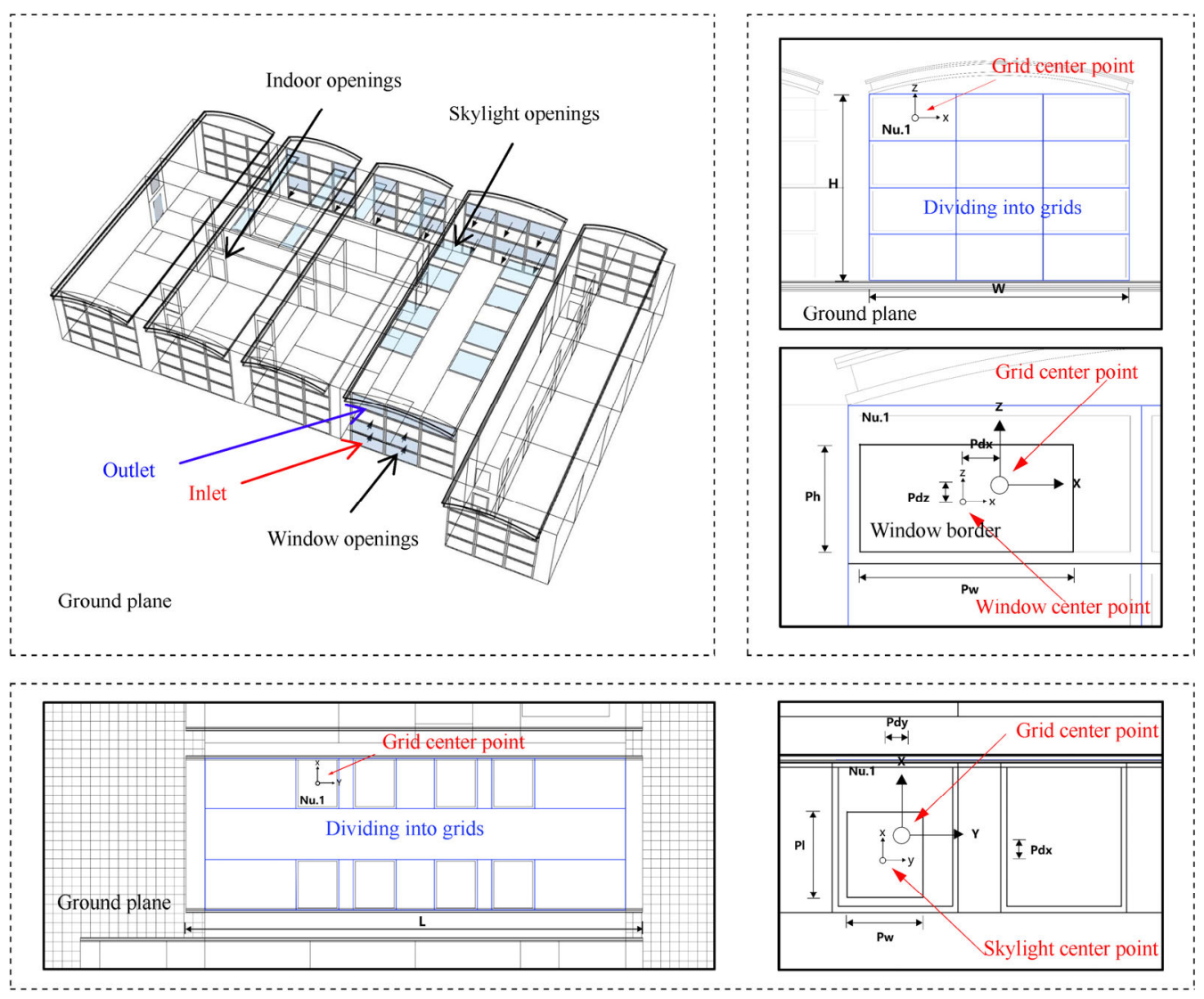

Fig. 4 Parameter design of the simulation experiment

Table 1 Building openings design geometry

\begin{tabular}{cccc}
\hline Name & Description & Unit & Initial value \\
\hline$P_{n a}$ & Number of window openings & & 23 \\
$P_{n b}$ & Number of skylight openings & & 14 \\
$P_{w a}$ & Window openings width & $\mathrm{m}$ & 2.5 \\
$P_{w b}$ & Skylight openings width & $\mathrm{m}$ & 2.2 \\
$P_{h}$ & Window openings height & $\mathrm{m}$ & 1.25 \\
$P_{l}$ & Skylight openings length & $\mathrm{m}$ & 2.5 \\
$W$ & Interface width & $\mathrm{m}$ & 8 \\
$H$ & Interface height & $\mathrm{m}$ & 5.8 \\
$L$ & Interface length & $\mathrm{m}$ & 22 \\
$P_{d x}$ & $x$-direction offset distance (window openings) & $\mathrm{m}$ & 0 \\
$P_{d z}$ & $z$-direction offset distance (window openings) & $\mathrm{m}$ & 0 \\
$P_{d x b}$ & $x$-direction offset distance (skylight openings) & $\mathrm{m}$ & 0 \\
$P_{d y}$ & $y$-direction offset distance (skylight openings) & $\mathrm{m}$ & 0 \\
\hline
\end{tabular}

Note: The area and position of indoor openings are calculated as constant.

\subsection{Conducting simulated experiments}

In the simulation experiment, we focused on standard scenarios (not health care settings for COVID-19 patients); thus, we assumed $I=1 . p$ is the pulmonary ventilation rate of each susceptible per hour $\left(\mathrm{m}^{3} / \mathrm{h}\right), p=0.3 \mathrm{~m}^{3} / \mathrm{h}$ when people are sitting or doing light activity indoors. Available reports and studies have shown that COVID-19 is consistent with respiratory infectious diseases' primary transmission mechanism (WHO 2020; Wu et al. 2020; Zhou et al. 2020); this infectious disease's quanta value has not been conclusively established at this stage. The quanta generation rate of COVID-19 has been obtained as $14-48 \mathrm{~h}^{-1}$ by Dai and Zhao (2020). In this study, the quanta generation rate was taken as $48 \mathrm{~h}^{-1}$ and brought into the experiment. The filtration efficiency of ordinary medical surgical masks on virusladen aerosols is about $60 \%$ (Hui et al. 2012), which can be set as $50 \%$ considering the influence of air leakage (Davies et al. 2013). The total number of susceptible people in the space was set at 30 , and the indoor air temperature was set at $21.5-23{ }^{\circ} \mathrm{C}$. The indoor relative humidity was set at $42 \%-55 \%$ by monitoring the environment in combination with the case building.

Based on available medical case report data (Wells 1934; Brundrett 1992; Fennelly and Nardell 1998), values were assigned to factors such as the number of susceptibles in the space, filtration efficiency, the exposure time, the value of virus quanta (COVID-19), and the virus survival rate in the air (related to the air environment and active antivirus measures), which were brought into the infection rate distribution model (Table 2). The vector airflow field effect 
on the virus infection rate distribution under the influence of different building opening parameters is investigated by fixing multiple sets of variables. In this paper, we have replaced the variables used to calculate the infection rate in Table 2 with a constant value, which can impact the accuracy of the infection rate calculation. In real-life situations, these variables are constantly changing dynamically. An in-depth discussion of personnel activity information, personnel protection behavior against viruses, and virus survival rates could lead to more accurate infection rate calculations. However, the results of the experiments in this paper are designed to explore the changing trend of infection rates, not the true infection rates which are used for medical prediction, so these variables have been simplified in the experimental design, and this simplification would not affect the changing trend of virus infection rates.

Firstly, the case building's opening parameters (initial values) are brought into the infection rate distribution model. Then we perform simulation experiments using the simulation scenario program built by Grasshopper technology. Since the experimental case is a kindergarten building that serves the population of children, we place the plane for testing the concentration of virus-carrying particles at a horizontal height of $1 \mathrm{~m}$ and set up 6583 test points to monitor the quanta concentration. In the experiment, under the condition that the input and output openings were fixed, the wind speed values at the input openings were limited to $1.0-2.3 \mathrm{~m} / \mathrm{s}$ (August), $0.7-1.8 \mathrm{~m} / \mathrm{s}$ (September), and 1.6-2.5 m/s (October). Then we simulated and calculated the distribution of infection rates in the room under the three conditions (Figure 5).

Table 2 Predefined experimental conditions based on medical data

\begin{tabular}{|c|c|c|c|c|c|c|}
\hline Region & No. of susceptible & Filtration efficiency & Exposure period(h) & $-k N$ & $p\left(\mathrm{~m}^{3} / \mathrm{h}\right)$ & $q\left(\mathrm{~h}^{-1}\right)$ \\
\hline $\mathrm{a}$ & 12 & $0 / 0.5$ & 1.0 & \multirow{4}{*}{$\mathrm{d} N / \mathrm{d} t$} & 0.3 & 48 \\
\hline $\mathrm{b}$ & 10 & $0 / 0.5$ & 1.0 & & 0.3 & 48 \\
\hline c & 4 & $0 / 0.5$ & 1.0 & & 0.3 & 48 \\
\hline d & 4 & $0 / 0.5$ & 1.0 & & 0.3 & 48 \\
\hline
\end{tabular}
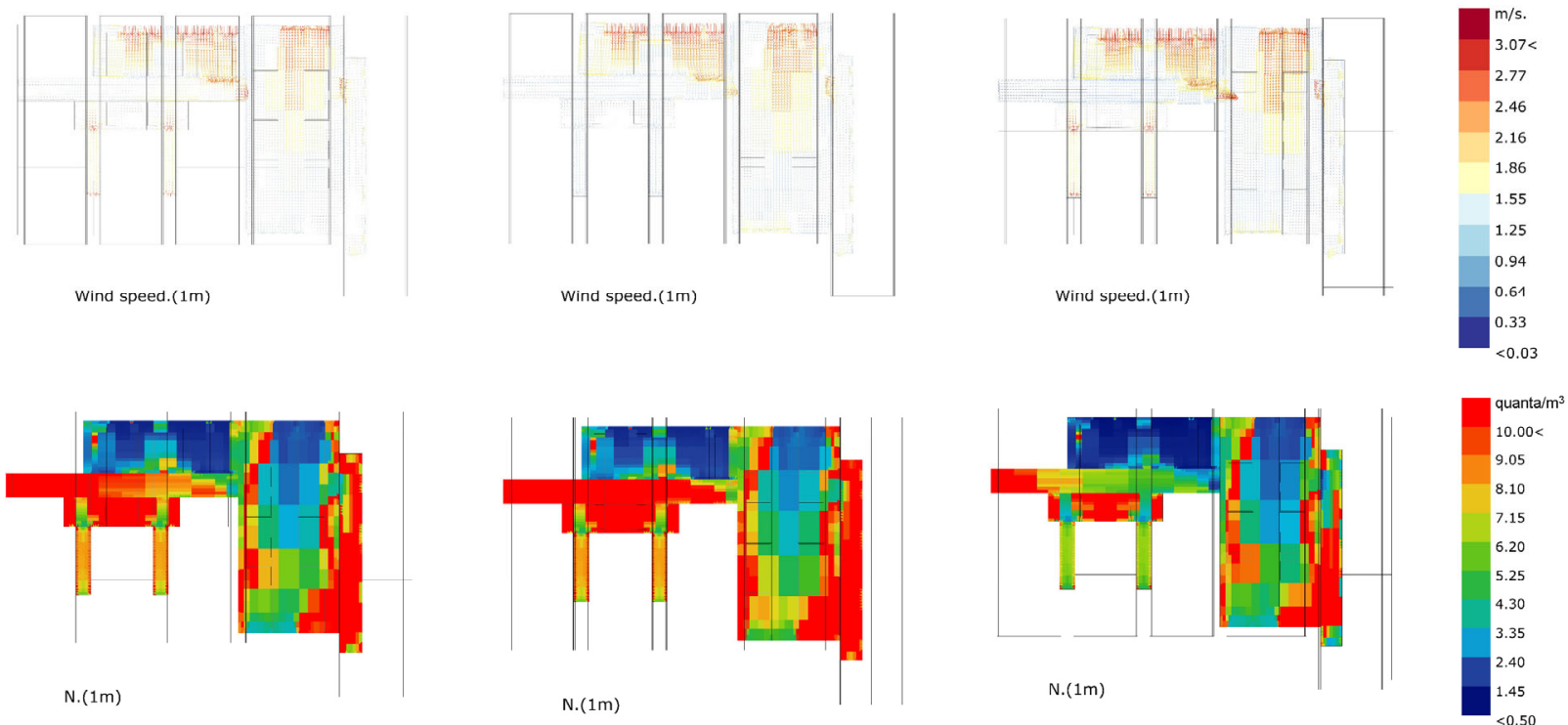

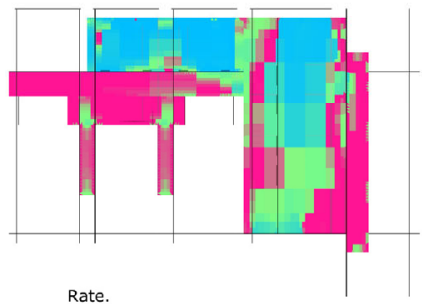

$1.0-2.3 \mathrm{~m} / \mathrm{s}$ (August)

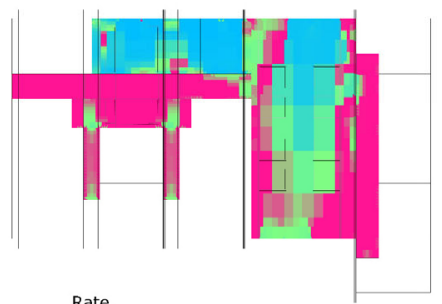

$0.7-1.8 \mathrm{~m} / \mathrm{s}$ (September)

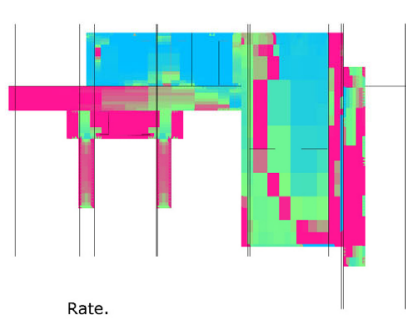

$1.6-2.5 \mathrm{~m} / \mathrm{s}$ (October)

Fig. 5 Infection rate distribution of building openings design parameters under initial value 


\section{Results}

4.1 Results of the distribution of infection rates before optimization

Based on the simulation results, we can obtain an overall quantified average wind speed of the building transition spaces in three different months of $0.61 \mathrm{~m} / \mathrm{s}$ (August), $0.53 \mathrm{~m} / \mathrm{s}$ (September), and $0.81 \mathrm{~m} / \mathrm{s}$ (October). The concentration of virus-carrying particles in the space was 10.05 quanta $/ \mathrm{m}^{3}$ (August), 11.81 quanta $/ \mathrm{m}^{3}$ (September), and 6.62 quanta $/ \mathrm{m}^{3}$ (October). The average infection rate in space was $8.10 \%$ (August), 9.34\% (September), and 7.33\% (October). We found that Regions $\mathrm{c}$ and $\mathrm{d}$ have a higher infection rate because they have only one opening directly connected to the building exterior. The airflow field in space is mainly formed by building openings connected to other regions, and the vector wind velocity is low. Regions a and $b$, on the other hand, are more open on the spatial scale, with 27 openings directly connected to the exterior of the building (15 window openings and 12 skylight openings). The average value of the infection rate in this region is lower than in Regions $c$ and $d$. Regions $a$ and $b$ have to consider the function of children's indoor activities, and the number of susceptible persons is 22 , so the airflow environment in this region is very demanding. Based on the simulation results, it was found that the distribution of infection rates in the area is uneven, and there are several areas with high and low infection rates, ranging from $83.99 \%$ to $0.63 \%$, which increases the risk of infection in the space.

In summary, the current rate of indoor infection in buildings shows three characteristics. Firstly, the infection rate is much higher in the narrower corridor spaces than in the atrium spaces of the building. Secondly, the average infection rate in the building's traffic spaces is high; even in October, when outdoor wind speeds are high, the infection rate can still be up to $7.33 \%$. Thirdly, there is an uneven distribution of infection rates in the indoor spaces, as we can see in Figure 5, which shows that there are areas where the infection rate is much higher than the average. We believe that the distribution of infection rates has a more significant impact on the risk of infection indoors than the average value of infection rates. Such a distribution of infection rates in current buildings actually poses a very high risk of infection.

4.2 Results of the distribution of infection rates after optimization

Optimization experiments on building openings design were carried out using the Grasshopper program and the Genetic Algorithm program. Setting the openings' geometric parameters as the optimization variables (Table 3 ) to reduce the average concentration of virus-carrying particles on the test plane allows multiple sets of variables to be optimally combined within the range of values taken.

Table 3 Optimized openings geometry of the building

\begin{tabular}{|c|c|c|c|c|c|c|}
\hline Name & Unit & Range & Influence relation & Limitation & Optimized value & Variations \\
\hline$P_{\text {na }}$ & & 15 to 36 & & & 32 & +11 \\
\hline$P_{n b}$ & & 14 & & & 14 & 0 \\
\hline$P_{w a}$ & $\mathrm{~m}$ & 2.0 to 2.5 & & $3 \times P_{w a}<8.0$ & 2.5 & 0 \\
\hline$P_{w b}$ & $\mathrm{~m}$ & 2.2 & & $2 \times P_{w b}<8.0$ & 2.2 & 0 \\
\hline$P_{h}$ & $\mathrm{~m}$ & 1 to 1.5 & & $4 \times P_{h}<5.8$ & 1.4 & +0.15 \\
\hline$P_{l}$ & $\mathrm{~m}$ & 2.5 to 4 & & $4 \times P_{l}<22$ & 3.4 & +0.9 \\
\hline$W$ & $\mathrm{~m}$ & 8 & $\begin{array}{l}W=P_{n a} \times P_{w a}+D_{1 a}+2 D_{2 a} \\
W=P_{n b} \times P_{w b}+D_{1 b}+2 D_{2 b}\end{array}$ & & 8 & 0 \\
\hline$H$ & $\mathrm{~m}$ & 5.8 & $H=P_{n a} \times P_{h}+D_{3}+2 D_{4}$ & & 5.8 & 0 \\
\hline$L$ & $\mathrm{~m}$ & 22 & $L=P_{n b} \times P_{l}+D_{5}+2 D_{6}$ & & 22 & 0 \\
\hline$P_{d w}$ & $\mathrm{~m}$ & -0.10 to 0.10 & & $\left|P_{d x}\right|<W / 6-P_{w a} / 2$ & -0.03 & -0.03 \\
\hline$P_{d h}$ & $\mathrm{~m}$ & -0.22 to 0.22 & & $\left|P_{d z}\right|<H / 8-P_{h} / 2$ & 0.12 & +0.12 \\
\hline$P_{d w b}$ & $\mathrm{~m}$ & -0.9 to 0.9 & & $\left|P_{d x b}\right|<W / 4-P_{w b} / 2$ & 0.2 & +0.2 \\
\hline$P_{d l}$ & $\mathrm{~m}$ & $-1.5 \sim 1.5$ & & $\left|P_{d y}\right|<L / 8-P_{l} / 2$ & -1.1 & -1.1 \\
\hline
\end{tabular}

Note: $D_{1 a}$ is the distance between window openings in the $x$-direction, and $D_{2 a}$ is the distance between window openings to the interface boundary. $D_{1 b}$ is the distance between skylight openings in the $x$-direction, and $D_{2 b}$ is the distance between skylight openings to the interface boundary. $D_{3}$ is the distance between window openings in the $z$-direction, and $D_{4}$ is the distance between window openings to the interface boundary. $D_{5}$ is the distance between skylight openings in the $y$-direction, and $D_{6}$ is the distance between skylight openings to the interface boundary. 
A set of solutions for the design parameters of building openings with the lowest risk of viral infection was found (Table 3). In the optimization results of this experiment, the size of the window openings changed less. In contrast, the number of openings and the location information were significantly different from the parameters' initial values. The optimized values show that the design solution with the lowest infection rate is not to increase the number of windows to the maximum but to open windows in the best position on a divided grid. This solution maximizes the efficiency of resource utilization.

Based on the optimized results, we can obtain an overall quantified average wind speed of the building transition spaces in three different months of $0.85 \mathrm{~m} / \mathrm{s}$ (August), $0.71 \mathrm{~m} / \mathrm{s}$ (September), and $0.95 \mathrm{~m} / \mathrm{s}$ (October). The concentration of virus-carrying particles in the space was 5.26 quanta $/ \mathrm{m}^{3}$ (August), 7.29 quanta $/ \mathrm{m}^{3}$ (September), and 4.83 quanta $/ \mathrm{m}^{3}$ (October). The average infection rate in space was $4.54 \%$ (August), 5.82\% (September), and 4.22\% (October). According to the optimization results, the infection rate in Region $b$ remains at a low level, with no significant changes compared to the pre-optimization period. Due to the large variation in the openings parameter in Regions a, c, d, the airflow field within this area varies significantly. As a result, the spatial distribution of virus particle concentrations and infection rates in these regions changed significantly compared to the pre-optimization period, showing low values and uniformity (Figure 6), with a significant reduction in the original high-risk areas in space, especially at the turn of the space.

\subsection{Comparative analysis of data}

By analyzing the simulated data from all monitoring sites and excluding the $5 \%$ invalid cases, we can discuss the infection rate values for each region in the space in more depth (Figure 7). The mean infection rates for the four regions in the building transition spaces before optimization were $5.02 \%, 1.93 \%, 10.28 \%$ and $18.73 \%$ (August); $5.76 \%, 2.14 \%$, $11.84 \%$ and $23.13 \%$ (September); $3.92 \%, 1.53 \%, 8.67 \%$ and $12.10 \%$ (October), respectively. The overall infection rate in the transition spaces was $6.71 \%, 7.87 \%$, and $5.23 \%$. The mean infection rates in the four regions of the transition spaces after optimization were $3.40 \%, 2.35 \%, 5.93 \%$ and $4.11 \%$ (August); 4.08\%, 2.62\%, 7.74\% and 4.72\% (September); $3.61 \%, 2.03 \%, 4.79 \%$ and $3.87 \%$ (October), respectively. The overall infection rate in the transition spaces was $3.97 \%$, $4.87 \%$, and $3.67 \%$. By comparing the values of virus infection rate before and after optimization, we can find that the overall

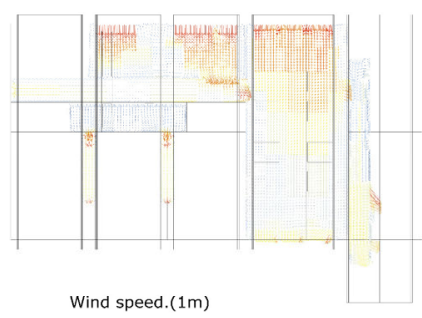

Wind speed.(1m)
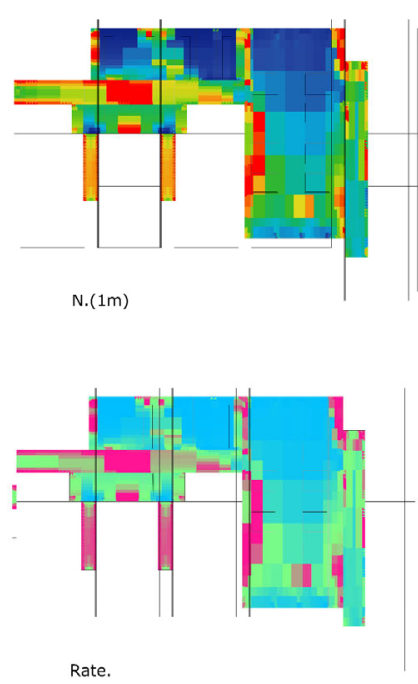

$1.0-2.3 \mathrm{~m} / \mathrm{s}$ (August)

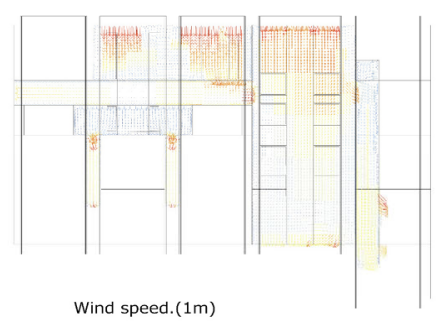

Wind speed.(1m)

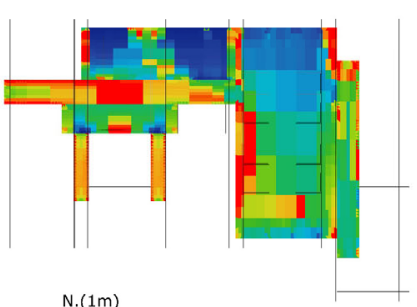

N.(1m)

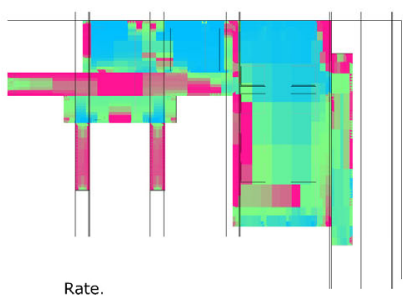

$0.7-1.8 \mathrm{~m} / \mathrm{s}$ (September)
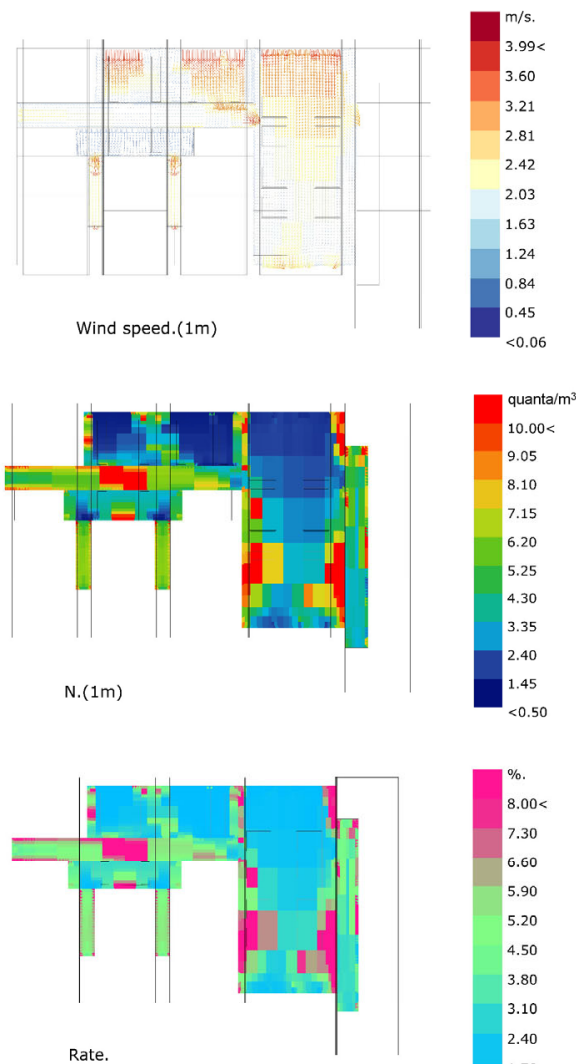

$1.6-2.5 \mathrm{~m} / \mathrm{s}$ (October) m/s.
$3.99<$
3.60
3.21
2.81
2.42
2.03
1.63
1.24
0.84
0.45
$<0.06$

$q u a n t a /$
$10.00<$
9.05
8.10
7.15
6.20
5.25
4.30
3.35
2.40
1.45
$<0.50$

$\%$
$8.00<$
7.30
6.60
5.90
5.20
4.50
3.80
3.10
2.40
1.70
$<1.00$

Fig. 6 Infection rate distribution of building openings design parameters under optimized values 
average infection rate of the transition space decreased by $2.74 \%, 3.00 \%$, and $1.51 \%$ after the building openings optimization, with the values of Regions $\mathrm{c}$ and d decreasing significantly by $4.35 \%, 4.10 \%$, and $3.88 \%$ in Region c, and by $14.62 \%, 18.41 \%$, and $14.62 \%$ in Region $\mathrm{d}$, respectively. $8.23 \%$. However, before optimization, the infection rates in Regions $\mathrm{c}$ and $\mathrm{d}$ were very high, 3.57\%, 3.97\%, 3.44\%, and $12.02 \%, 15.25 \%, 6.87 \%$ higher than the average infection rates in the transition space, respectively. However, after optimization, their infection rates differed only by $1.96 \%$, $2.87 \%, 1.12 \%$, and $0.14 \%, 0.45 \%, 0.20 \%$, respectively, from the overall average of the space.
Simultaneously, based on the results of the SPSS data analysis, we can find that the degree of fluctuation of infection rate values in the space decreased significantly after the optimization of the building openings (Figure 8), as reflected by the fact that its minimum, first quartile, third quartile, and maximum values were all close to the median. After optimization, the average value, median, maximum, range, and interquartile range of the infection rate values are all significantly lower. The variance after optimization decreased by $74.62 \%, 60.97 \%$, and $44.72 \%$ compared with the values before optimization, respectively (Figure 8). Therefore, the numerical analysis shows that the optimized building
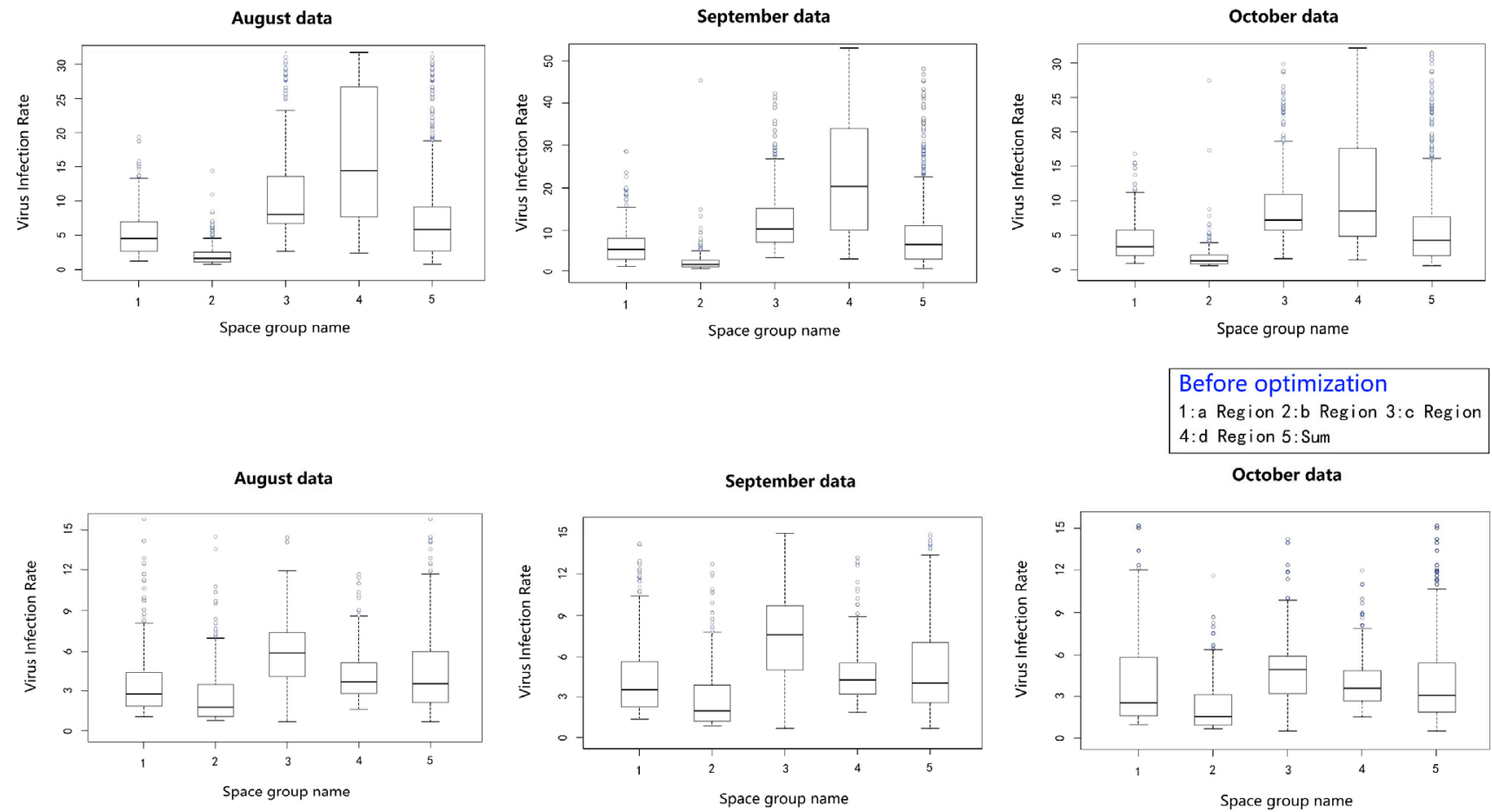

After optimization
1:a Region $2:$ b Region $3: c$ Region
$4: \mathrm{d}$ Region $5:$ Sum

Fig. 7 Variations of virus infection rate before and after optimization
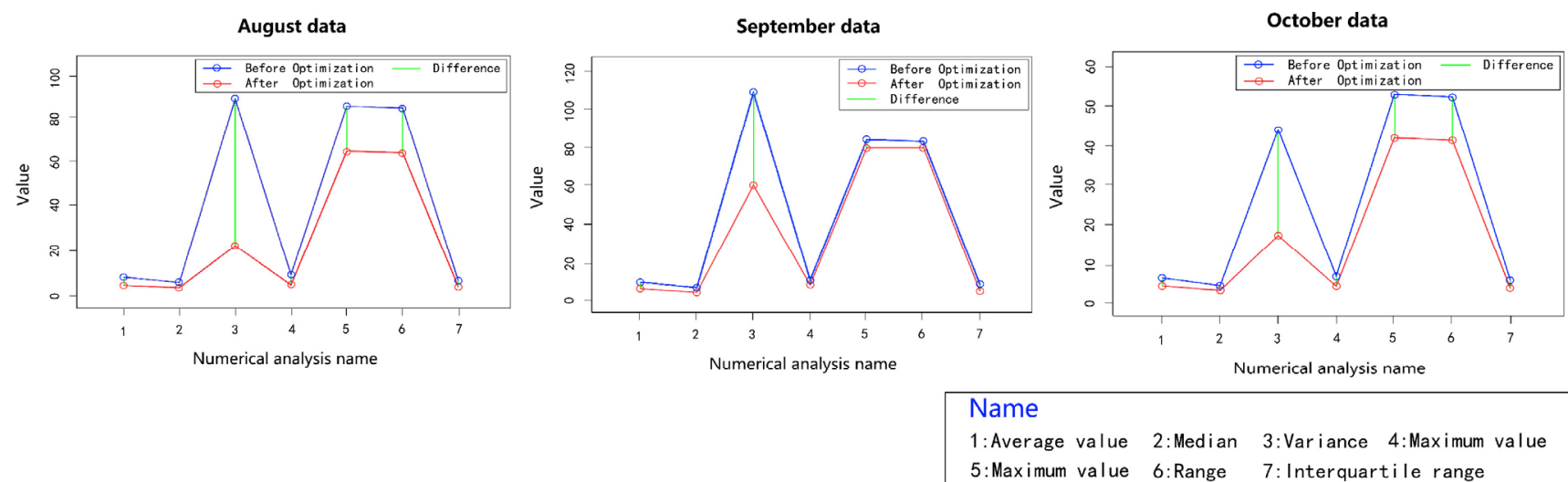

Fig. 8 The value difference in respect to optimization 
opening parameters can correspond to a lower mean infection rate and a lower risk (uniform) infection rate distribution.

In summary, the building situation after parameter optimization shows that the three characteristics of the original building indoor infection rate results are better addressed. Although Region d is a long and narrow corridor space, we have reduced the average infection rate in this area by adjusting its opening parameters to bring it closer to the average value. At the same time, the average infection rate in the space drops significantly, even in September. When the outdoor wind speed is at its lowest, the infection rate is only $5.82 \%$. While in August and October, the average indoor infection rate is below $5 \%$. Concerning the indoor infection rate distribution, the optimized parameter building has a more even distribution of indoor infection rates, and the risk of virus infection is significantly lower than that in the original building. In this part, an interesting phenomenon can be observed. While the parameter optimization experiment greatly affected the infection rate for space as a whole and specific areas a, $c$ and d, it did not substantially affect area b. It also indicates that the parametric optimization model is more sensitive to the effects of the higher risk areas.

\section{Discussion}

The final results presented by our experiments show that the evaluation criteria for finding cases with the lowest risk of infection are the value and distribution of the infection rate. In contrast to previous studies evaluating the risk of virus infection in hospital wards (Qian et al. 2009; Chavez et al. 2011; Du et al. 2020), this experiment uses the same evaluation criteria, i.e., the trend of decreasing risk of infection through the average infection rate values and the volatility of the data. Unlike the previous studies, the optimal case selected for this experiment provides not only the room's ventilation parameters but also the specific values of the building design parameters directly. The results of the variation in the values of the design parameters can help us gain a more in-depth understanding of the influence of the building design plan on the risk of infection. For example, the best case in this experiment is not the one with the highest number of window openings, which indicates that the ability of the building opening location parameter to influence the results is, in some cases, even higher than the number of building openings. By analyzing the design parameters more closely, we find that in many specific cases, the ability of the design parameters to influence the risk of infection is different from what we routinely perceive. Therefore, the findings of this study can better help us explore the direction of optimization in building design.

In the following subsections, we will discuss the limitations of parametric optimization experiments in this study and the possible future research directions.

\subsection{Limitations}

In the present experiments, we have the following three presuppositions. The first assumption that the viral quanta produced by an infected person for a limited period in the absence of airflow influence are uniformly distributed across all grids in space. An airflow field is then introduced to redistribute the virus-bearing particles in space under the airflow's influence to study the concentration of virusbearing particles or quanta concentration (quanta/ $\mathrm{m}^{3}$ ) in different grids in space. Finally, we can calculate the risk of infection. In the above process, the effect of the free movement of the infected person is ignored. In contrast, in the real situation, the infected person's trajectory can significantly impact the quanta concentration in the region, so this experimental design may underestimate the susceptibility risk of approaching patients.

The second assumption is to take a simple value for the viral mortality rate in calculating quanta concentrations. Several factors can influence the constant mortality rate of airborne viruses. In addition to the air's relative humidity and temperature, the biological nature of the virus itself, disinfection, and other anthropogenic measures increase airborne microorganisms' mortality rate (Riley 1974; Brundrett 1992). When the virus atomizes into the air, the rate of death is at first very fast and then gradually slows down (Brundrett 1992). The first quick period is short and corresponds to the evaporation process when the droplets are almost dry. In the present study, we only studied the disease transmitted by droplet nuclei and ignored the droplets' evaporation process. In a real indoor environment (Wells 1934), droplets smaller than $100 \mu \mathrm{m}$ would dry within 5 seconds, and droplets more massive than $100 \mu \mathrm{m}$ would be concentrated at a plane $2 \mathrm{~m}$ above the ground. However, our experiment's test plane was set at $1 \mathrm{~m}$ from the floor because it was targeted at the child population, so that this experimental design may have underestimated the concentration distribution of the virus in space.

The third assumption is that airborne viruses attach to tiny particles or droplet nuclei (Wells 1934; Brundrett 1992). We assume that the distribution of airborne virus is similar to the distribution of particles. Experimentally, we bring in the dispersion coefficient between viruses and particles as a specific constant. We use aerodynamic equations to calculate particles' transport by air currents, thus spreading and influencing virus particles. In the real case, there is a degree of dispersion between viruses and particles related to the effective viscosity $\left(\mu_{\text {eff }}\right)$ between microorganisms and particles. Therefore the replacement of constants here may affect the accuracy of the infection rate. 
In summary, the main difference between the experimental results and the actual situation would arise from the experimental assumption that the activity of susceptible people is ignored. Not counting the specific activity trajectories of infected and exposed individuals is also one of the main limitations of the Wells-Riley model due to the random nature of population activity in the actual situation in the space cannot be fully quantified. The research on the relationship between design parameters and infection rates in this paper aims to reduce the risk of indoor virus infection by optimizing building design solutions. The increase in infection rates at specific locations in the room due to the activity of susceptible people is incidental. It does not affect the trend of infection rate changes in a space over time as the airflow environment does. The control of population behavior is also not the research question we would like to discuss in this paper. Therefore, the primary purpose of the experimental results in this paper is to reflect the virus infection rate trend to help researchers determine the direction of building design optimization. The virus infection rates in this paper should not be directly applied to precise medical statistics.

\subsection{Development}

There are many aspects of this research that could be explored in-depth in the future. First, the multiple coefficients used in the experiments for infection rate calculations, which are used as deterministic constants in this paper as a proxy for the calculations, should be investigated more depth. Numerical justification of these coefficients could bring the simulation results of infection rates closer to the actual situation. Secondly, we should also continue to enrich the discussion on the values of the parameters of building openings. In this study, the experimental simulation and optimization object is an existing building. The range of parameter values needs to be designed with the existing building structure in mind, so the range of variation of building opening parameters is limited. The offset parameter that controls the position of the openings on the facade is minimal, limiting the range of variation of the results to a certain extent. But, there is a more excellent range of variation in the parameter variables for a new building, making the effect of building openings on indoor viral infection rates more pronounced. It is essential to note here that this study is based on a small number of cases and some critical assumptions. Therefore, additional cases and more in-depth exploration are needed in the future.

\section{Conclusion}

This paper takes the example of a medium-sized kindergarten project in Germany. We focus on improving buildings' passive epidemic-proofing capacity, developing a viral infection rate calculation model combined with parametric optimization techniques to explore architectural design methods that can reduce the risk of virus infections in public areas. The study extracts the geometric parameters of the building openings in transition spaces. We then optimize them with the Grasshopper technique to explore the relationship between geometric parameter variation and the distribution of infection rates in the indoor space. The experiments show that the average virus infection rate in space after parameter optimization can be reduced by $3 \%$. This number in many special areas is up to $18.41 \%$. The variance of the infection rate values in the area can be reduced by up to $74.62 \%$. Analysis of the data shows that the design parameters of building openings can directly influence the risk of indoor respiratory virus transmission. The model is more effective in optimizing the distribution of indoor infection rates than reducing infection rate values, especially in areas at high risk of infection.

Current research shows that it is of significant research and practical value to explore passive-based architectural design solutions to control epidemics in the context of global epidemic cyclical outbreaks. In this study, we use a modified Wells-Riley model in our calculation. Previously, Air Changes Per Hour (ACH) method was used to calculate the infection rate by bringing the amount of ventilation in the space into the Wells-Riley model. In contrast, the new model in our study allows the dynamically wind speed to be substituted as a variable in the calculation equation. The $\mathrm{ACH}$ method uses the value of ventilation in the space for the calculation, so it can only obtain a value for the overall infection rate in the space and cannot show the distribution of the infection rate (Buchan et al. 2020; Mousavi et al. 2020; Wald et al. 2020). This method is more suitable for studying proactive operational strategies such as conditioning system operation methods and window opening and ventilation schemes. In contrast, the new model used in this paper replaces the original space ventilation with the air velocity at each point in the space and brings it into the calculation, thus analyzing the distribution of the infection rate in different areas of the space. This approach is more suitable for exploring the effects of changes in building design parameters on the infection rate in different areas of the room and is conducive to exploring the direction of optimizing passive design. The in-depth study of the relationship between design parameters and the risk of viral infection is an entirely new direction for research in this field and an important topic for future social and natural sciences research.

\section{Acknowledgements}

Thanks to Architecture + Light + Energy studio at Hochschule Wismar for the information on the case project drawings. 
This project was financially supported by the General Program of National Natural Science Foundation of China (No. 51978421) and the Key Research and Development Project in Tianjin (No. 20YFYSGX00020)

\section{References}

Balaras C, Droutsa P, Dascalaki E, et al. (2005). Service life of building elements \& installations in European apartment buildings. In: Proceedings of the 10th International Conference on Durability of Building Materials and Components (10DBMC), Lyon, France.

BBC News (2020). Coronavirus: Childcare uncertainty 'could block parents' work return'. BBC News. Available at https://www.bbc. com/news/uk-wales-53973672

Bjørn E, Nielsen PV (2002). Dispersal of exhaled air and personal exposure in displacement ventilated rooms. Indoor Air, 12: $147-164$.

Brundrett GW (1992). Legionella and Building Services. Oxford, UK: Butterworth Heine-mann.

Buchan AG, Yang L, Atkinson KD (2020). Predicting airborne coronavirus inactivation by far-UVC in populated rooms using a high-fidelity coupled radiation-CFD model. Scientific Reports, 10: 19659.

Chan-Yeung M, Xu R (2003). SARS: Epidemiology. Respirology, 8: S9-S14.

Chavez M, Hajra B, Stathopoulos T, et al. (2011). Near-field pollutant dispersion in the built environment by CFD and wind tunnel simulations. Journal of Wind Engineering and Industrial Aerodynamics, 99: 330-339.

Chen N, Zhou M, Dong X, et al. (2020). Epidemiological and clinical characteristics of 99 cases of 2019 novel coronavirus pneumonia in Wuhan, China: A descriptive study. The Lancet, 395: 507-513.

Dai H, Zhao B (2020). Association of the infection probability of COVID-19 with ventilation rates in confined spaces. Building Simulation, 13: 1321-1327.

Davies A, Thompson KA, Giri K, et al. (2013). Testing the efficacy of homemade masks: Would they protect in an influenza pandemic? Disaster Medicine and Public Health Preparedness, 7: 413-418.

Du Y, Blocken B, Pirker S (2020). A novel approach to simulate pollutant dispersion in the built environment: Transport-based recurrence CFD. Building and Environment, 170: 106604.

Ercan B, Elias-Ozkan ST (2015). Performance-based parametric design explorations: A method for generating appropriate building components. Design Studies, 38: 33-53.

Fennelly KP, Nardell EA (1998). The relative efficacy of respirators and room ventilation in preventing occupational tuberculosis. Infection Control and Hospital Epidemiology, 19: 754-759.

Fisk WJ, Seppanen O, Faulkner D, et al. (2003). Economizer system cost effectiveness Z: Accounting for the influence of ventilation rate on sick leave. Report no. LBNL-53192, Lawrence Berkeley National Laboratory, USA.

Gao NP, Niu JL (2007). Modeling particle dispersion and deposition in indoor environments. Atmospheric Environment, 41: 3862-3876.

Holmberg S, Li Y (1998). Modelling of the indoor environmentParticle dispersion and deposition. Indoor Air, 8: 113-122.
Hu F, Zheng X (2015). Carbon emission of energy efficient residential building. Procedia Engineering, 121: 1096-1102.

Huang L (2020). The impact of the COVID-19 pandemic on early education institutions in the United States-A statement by the head of an early childhood education institution. United Nations News. Available at https://news.un.org/zh/story/2020/05/1056712

Hui DS, Chow BK, Chu L, et al. (2012). Exhaled air dispersion during coughing with and without wearing a surgical or N95 mask. PLoS One, 7: e50845.

Ji Y, Qian H, Ye J, et al. (2018). The impact of ambient humidity on the evaporation and dispersion of exhaled breathing droplets: A numerical investigation. Journal of Aerosol Science, 115: 164-172.

Lai ACK, Wong SL (2010). Experimental investigation of exhaled aerosol transport under two ventilation systems. Aerosol Science and Technology, 44: 444-452.

Liu F, Zhang C, Qian H, et al. (2019). Direct or indirect exposure of exhaled contaminants in stratified environments using an integral model of an expiratory jet. Indoor Air, 29: 591-603.

Mills CE, Robins JM, Lipsitch M (2004). Transmissibility of 1918 pandemic influenza. Nature, 432: 904-906.

Mousavi ES, Pollitt KJG, Sherman J, et al. (2020). Performance analysis of portable HEPA filters and temporary plastic anterooms on the spread of surrogate coronavirus. Building and Environment, 183: 107186 .

Mui KW, Wong LT, Wu CL, et al. (2009). Numerical modeling of exhaled droplet nuclei dispersion and mixing in indoor environments. Journal of Hazardous Materials, 167: 736-744.

Nielsen PV, Zajas JJ, Litewnicki M, et al. (2014). Breathing and cross-infection risk in the microenvironment around people. In: Proceedings of ASHRAE Winter Conference, NY-14-C020, New York, USA.

Noakes CJ, Sleigh PA (2009). Mathematical models for assessing the role of airflow on the risk of airborne infection in hospital wards. Journal of the Royal Society Interface, 6(suppl_6): S791-S800.

Olsen SJ, Chang H-L, Cheung TY-Y, et al. (2003). Transmission of the severe acute respiratory syndrome on aircraft. New England Journal of Medicine, 349: 2416-2422.

Pavón RM, Alvarez AAA, Alberti MG(2020). Possibilities of BIM-FM for the management of COVID in public buildings. Sustainability, 12: 9974 .

Qian H, Nielsen PV, Li Y, et al. (2004). Airflow and contaminant distribution in hospital wards with a displacement ventilation system. In: Proceedings of the 2nd International Conference on Built Environment and Public Health (BEPH2004), Shenzhen, China.

Qian H, Li Y, Nielsen PV, et al. (2008). Dispersion of exhalation pollutants in a two-bed hospital ward with a downward ventilation system. Building and Environment, 43: 344-354.

Qian H, Li Y, Nielsen PV, et al. (2009). Spatial distribution of infection risk of SARS transmission in a hospital ward. Building and Environment, 44: 1651-1658.

Redrow J, Mao S, Celik I, et al. (2011). Modeling the evaporation and dispersion of airborne sputum droplets expelled from a human cough. Building and Environment, 46: 2042-2051.

Riley RL (1974). Airborne infection: Transmission and control. The American Journal of Medicine, 57: 466-475. 
Riley EC, Murphy G, Riley RL (1978). Airborne spread of measles in a suburban elementary school. American Journal of Epidemiology, 107: 421-432.

Rudnick SN, Milton DK (2003). Risk of indoor airborne infection transmission estimated from carbon dioxide concentration. Indoor Air, 13: 237-245.

Srebric J, Vukovic V, He G, et al. (2008). CFD boundary conditions for contaminant dispersion, heat transfer and airflow simulations around human occupants in indoor environments. Building and Environment, 43: 294-303.

Valerie B (2021). Remote kindergarten during Covid-19 'Could impact this generation of kids for their lifetime'. The Wall Street Journal. Available at https://www.wsj.com/articles/remotekindergarten-during-covid-19-could-impact-this-generation-ofkids-for-their-lifetime-11620552653

Valleron A-J, Cori A, Valtat S, et al. (2010). Transmissibility and geographic spread of the 1889 influenza pandemic. Proceedings of the National Academy of Sciences, 107: 8778-8781.

Wald SH, Arthofer R, Semple AK, et al. (2020). Determination of length of time for "postaerosol pause" for patients under investigation or positive for COVID-19. Anesthesia \& Analgesia, 131: e94-e96.

Wei J, Li Y (2015). Enhanced spread of expiratory droplets by turbulence in a cough jet. Building and Environment, 93: 86-96.

Wells WF (1934). On air-borne infection: Study II: Droplets and droplet nuclei. American Journal of Epidemiology, 20: 611-618.

Wells WF (1955). Airborne Contagion and Air Hygiene: An Ecological
Study of Droplet Infection. Cambridge, MA, USA: Harvard University Press.

WHO (2020). Coronavirus Disease 2019 (COVID-19) Situation Report-30. Available at https://www.who.int/docs/default-source/ coronaviruse/situation-reports/20200219-sitrep-30-covid-19.pdf? sfvrsn=3346b04f_2

Wong TW, Lee CK, Tam W, et al. (2004). Cluster of SARS among medical students exposed to single patient, Hong Kong. Emerging Infectious Diseases, 10: 269-276.

Wu F, Zhao S, Yu B, et al. (2020). A new coronavirus associated with human respiratory disease in China. Nature, 579: 265-269.

Xie X, Li Y, Chwang ATY, et al. (2007). How far droplets can move in indoor environments-Revisiting the Wells evaporation-falling curve. Indoor Air, 17: 211-225.

Xu C, Wei X, Liu L, et al. (2020). Effects of personalized ventilation interventions on airborne infection risk and transmission between occupants. Building and Environment, 180: 107008.

Yu ITS, Wong TW, Chiu YL, Lee N, Li Y (2005). Temporal-spatial analysis of severe acute respiratory syndrome among hospital inpatients. Clinical Infectious Diseases, 40: 1237-1243.

Zhang J (2020). Integrating IAQ control strategies to reduce the risk of asymptomatic SARS CoV-2 infections in classrooms and open plan offices. Science and Technology for the Built Environment, 26: 1013-1018.

Zhou P, Yang X, Wang X, et al. (2020). A pneumonia outbreak associated with a new coronavirus of probable bat origin. Nature, 579: 270-273. 